\title{
The Effect of the Heat Treatment on the Dust Emission During Machining of an Al-7Si-Mg Cast Alloys
}

\author{
A. Djebara, Y. Zedan, J. Kouam, and V. Songmene
}

\author{
(Submitted May 21, 2013; in revised form July 19, 2013; published online August 17, 2013)
}

\begin{abstract}
This paper reports on the effect of artificial aging on the machinability of Al-7Si-Mg (A356) cast alloys for the as-received alloy, solution heat-treated (SHT) alloy and then aged SHT alloy at 155, 180, and $220^{\circ} \mathrm{C}$, respectively. The influence of heat treatment on the machinability of the alloys studied was considered using innovative criteria such as dust emission. The effect of various lubrication modes including dry, mist, and wet process, as well as cutting speed and feed rate, was also investigated. The results obtained from the statistically designed experiments indicate that at the same cutting conditions, the A356-T7 heat treatment generates less dust emission level compared to other various heat treatments (there is $32 \%$ less airborne swarf produced than with A356-T6). Aging at low temperature was observed to produce the greatest level of the dust emission while the aging at higher temperatures is accompanied by a reduction in the dust emission level. Fracture surface analysis using scanning electron microscope, has shown that dust emission levels were strongly dependent on the nature of the fracture surface of the alloys studied, with different heat treatments. A change in chip formation was also found to be a function of age hardening and dust emission during machining of the tested aluminum alloy. A correlation was established between the cutting speed, the feed rate, and the dust emission, which is useful for determining the conditions required for minimal dust emission.
\end{abstract}

Keywords air quality, aluminum alloys, artificial aging, cutting fluid, dust emission, drilling

\section{Introduction}

Over the years, the United States Environmental Protection Agency (EPA) has changed the focus of particulate standards from total airborne particles in 1971 to particles size lower than $10 \mu \mathrm{m}\left(\mathrm{PM}_{10}\right)$ in 1987 and then to $\mathrm{PM}_{2.5}$ (particles size lower than $2.5 \mu \mathrm{m}$ ) standard in 1997 (Ref 1). The shift toward regulating smaller particles is due to their longer residence time in the air, their chemical composition or interaction, and their deeper penetration into the respiratory system. Therefore, the modern metalworking performance cannot be measured based solely on criteria such as productivity, precision, surface quality, or cycle time. Machining shop indoor air quality and environment protection has become another machining process criterion that must be considered. For example, manufacturing industries are being forced to implement strategies to reduce the amount of cutting fluids used in their production lines and to limit the risk of exposition to fine and ultrafine metallic airborne particles. This can be done by controlling the machining parameters and cutting condition, but could also be done by controlling in the material properties and conditions

A. Djebara, Chemical and Biological Hazards Prevention Research (IRSST), 505 Boul. De Maisonneuve Ouest, Montréal, QC H3A 3C2, Canada; and Y. Zedan, J. Kouam, and V. Songmene, University of Quebec- ÉTS, Mechanical Engineering, 1100, rue Notre-Dame Ouest, Montréal, QC H3C 1K3, Canada. Contact e-mail: abdelhakim. djebara@irsst.qc.ca.
(Ref 2). The properties of various aluminum alloys can be altered by specific designated heat treatment. Some aluminum alloys can be solution-treated to increase their strength and hardness. The heat treatment process can be classified in two process, including solution heat treatment and artificial aging (Ref 3). The A356 aluminum alloy belongs to the Al-Si-Mg system, and is heat-treatable alloys owing to the presence of magnesium content, which combines with $\mathrm{Si}$ to form the $\mathrm{Mg}_{2} \mathrm{Si}$ precipitation hardening phase (Ref 4). Such alloys are subjected to solution heat treatment at temperatures close to the eutectic temperature, in order to obtain the maximum amount of $\mathrm{Mg}$ and $\mathrm{Si}$ in solid solution, as well as avoid localized melting at the grain boundaries (Ref 5). The solution heat treatment of Al-Si$\mathrm{Mg}$ alloys is carried out primarily for two reasons: the first is to dissolve $\mathrm{Mg}$ and $\mathrm{Si}$ to the maximum extent in the aluminum matrix, and the second is to alter the morphology of the eutectic Si particles from their acicular form in the as-cast condition to a finer and more spheroidized form (Ref 6). By heating the solution heat-treated (SHT) alloys to a temperature above room temperature and holding it there, the precipitation accelerates and the strength is further increased compared to natural aging and accompanied by significant drop in ductility. This is called artificial aging, age hardening or just aging and is generally carried out at temperature up to approximately $150{ }^{\circ} \mathrm{C}$ for Al-Si-Mg alloys (Ref 7).

The comparison between wet and dry machining reveals that wet machining produces much more aerosol than does dry machining - about 12-80 times in fact (Ref 8). Dry machining is becoming increasingly popular and has been made possible due to technological innovations (Ref 9). However, the problem of the solid aerosols still remains in the dry conditions that is accompanied by emissions of more solid fine dusts $\left(\mathrm{PM}_{2.5}\right.$, size is less than $2.5 \mu \mathrm{m}$ ), which are reachable, and penetrate deep into human lungs and cause various diseases (Ref 10). The dust 
concentrations, up to approximately $300 \mu \mathrm{g} / \mathrm{m}^{3}$, are generated when machining dusty materials such as graphite (Ref 11). The dust emission when machining iron, steel, and brass at higher speeds was found to contain large percentage of particles below 5 $\mu \mathrm{m}$ in size (Ref 12,13). Concentrations of dust emissions generated during machining of metallic parts have been found to depend on the workpiece materials and its conditions as well as cutting parameters applied. Khettabi et al. (Ref 14) also show that most particles generated (number) during orthogonal machining of A6061-T6 aluminum alloy, AISI1018 steel, AISI4140 Steel and gray cast iron are ultrafine particles of about $20 \mathrm{~nm}$ in aerodynamic diameter. Similarly, Kouam et al. (Ref 15) found that friction test using brittle aluminum alloys produces more ultrafine particles than microparticles. Balout et al. (Ref 16) studied how the machining parameters influence dust generation during dry machining. They reported that brittle materials generate fewer fine dust particulate (aerodynamic diameter lower than $2.5 \mu \mathrm{m}$ ) than ductile materials during machining process. This behavior was attributable to the difference in tool contact length (zone of secondary deformation and friction) and the high plastic deformation taking place during machining ductile materials. In another study, a correlation was found between chip formation and dust emission; the formation of a discontinuous chip being accompanied by a low emission level of a dust as was compared to the dust obtained when a long chip is formed (Ref 17). Khettabi et al. (Ref 18) conducted similar studies and concluded that the quantity and particle size of dust emission depend on cutting parameters, workpiece material, tool material, and geometry. They also showed that the intensity of dust emission increases with an increase of the cutting speed during turning and milling processes. Songmene et al. (Ref 19) identified several dust generation sources including, primary shear zone, chip surface, and the tool-work piece interface. Some dust generation sources have been evaluated friction at shear plane; the influence of the tribological conditions at the tool-chip interface; influence of tool wear resistance (Ref 20). Little or no work has been carried on studying the dust emission during machining of aged aluminum alloys. The main objective of this study was to evaluate the influence of machining conditions and cutting fluid on the emission metallic particles when machining of A356 aluminum alloy heat-treated at different conditions. In order to study this effect systematically, the aluminum alloy was heat-treated to produce different precipitation states and machined under controlled conditions. This work was carried out in order to minimize dust emission and improve air quality in machining shops.

\section{Experimental Procedure}

A set of experiments were carried out on a CNC milling machine tool (Power: $50 \mathrm{~kW}$, Speed: 28,000 rpm, Torque: $50 \mathrm{Nm}$ ). Sampling and collecting the metallic particles therefore requires an appropriate capture system. In this investigation the capture system used is appropriate to drilling processes. Dust sampling during machining was performed by pumping air from the cutting area (or near this area) via a DustTrak ${ }^{\mathrm{TM}}$ and a Micro-Orifice Uniform Deposit Impactor (MOUDI). DustTrak $^{\mathrm{TM}}$ was used to measure aerosols in a wide variety of

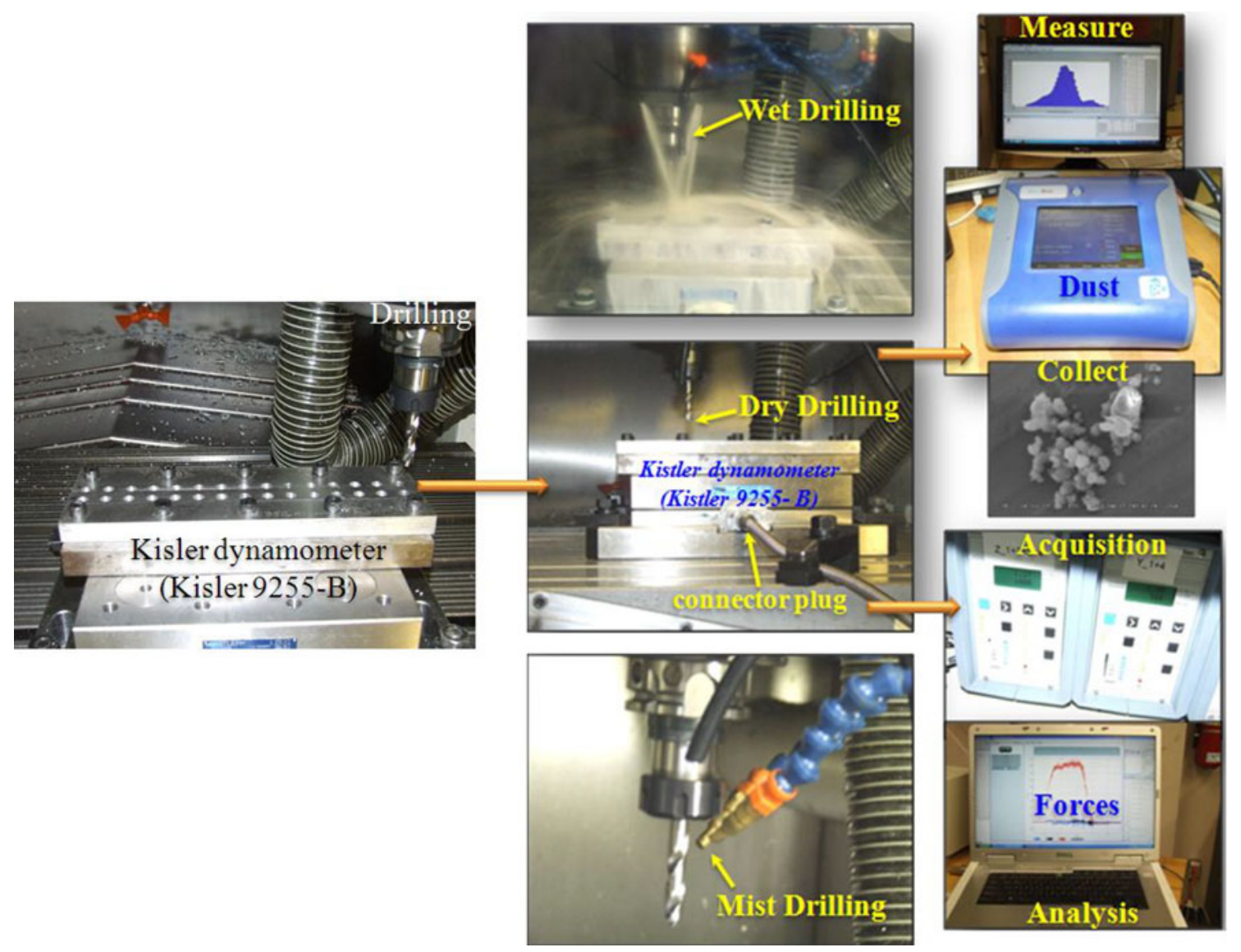

Fig. 1 Experimental setup 
environments, from the offices to the industrial workplaces. The DustTrak ${ }^{\mathrm{TM}}$ provides a real-time measurement of dust concentrations based on $90^{\circ}$ light-scattering laser photometer using a long wave length laser $(\lambda=780 \mathrm{~nm})$. The sampling was performed through the MOUDI stages, using cascade impaction to classify particles according to their aerodynamic diameters. Samples of particles during machining were collected on metal substrates. A pump was connected to the impactor to ensure particles collection for the MOUDI with a $30 \mathrm{~L} / \mathrm{min}$ of suction rate was used (Ref 21$)$. The dust sampling was carried out before, during, and after each cutting process to return to initial ambient concentration.

In the present work, cutting forces were measured using a threeaxis table dynamometer (Kistler 9255-B) on a machine table. The drilling performance was evaluated based on the total drilling force $\left(F_{\mathrm{t}}\right)$. The dust mass concentration was measured under dry, wet,

Table 1 Chemical composition of A356 alloy

\begin{tabular}{cccccccc}
\hline & Si & Mg & Fe & Cu & Mn & Zn & Al \\
\hline wt.\% & 7 & 0.35 & 0.2 & 0.2 & 0.1 & 0.1 & Balance \\
\hline
\end{tabular}

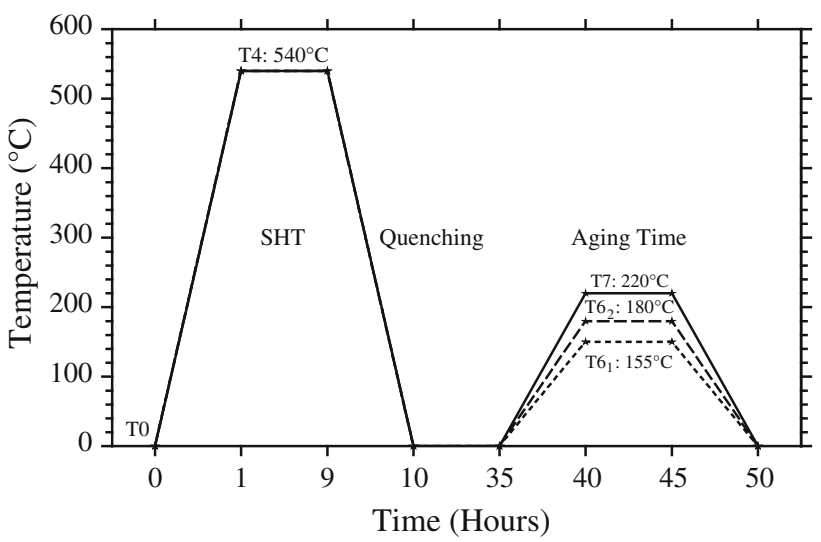

Fig. 2 Different heat treatments of A356 alloy and mist condition. The cutting tool used is non-coated high speed steel twist drills ( $3 / 8$ stub drill bright finish with 118 point angle). The parts used for the experiment were rectangular blocks of A356 cast aluminum alloy $300 \times 100 \times 20 \mathrm{~mm}$ in size, mounted on a special machining fixture; the experimental setup is shown in Fig. 1. The tested material was A356 aluminum alloy which chemical composition is given in Table 1 .

The A356 alloys was received in as-cast condition (T0), and the samples were then divided into five groups as follows: (i) two blocks in as-cast condition (T0); (ii) two blocks in T4 condition (solution heat-treated "SHT" + Quenching); (iii) two blocks in $\mathrm{T}_{1}$ condition (SHT + Quenching + Artificial aging at $155^{\circ} \mathrm{C}$ for $5 \mathrm{~h}$ ); (iv) two blocks in $\mathrm{T} 6_{2}$ condition $\left(\mathrm{SHT}+\right.$ Quenching + Artificial aging at $180{ }^{\circ} \mathrm{C}$ for $5 \mathrm{~h}$ ); and (v) two blocks in $\mathrm{T} 7$ condition (SHT + Quenching + Artificial aging at $220{ }^{\circ} \mathrm{C}$ for $5 \mathrm{~h}$ ). All the samples were SHT at $540{ }^{\circ} \mathrm{C}$, for solution times of $10 \mathrm{~h}$. The solution-treated samples were then quenched in warm water $\left(60^{\circ} \mathrm{C}\right)$ to room temperature. For each given condition, all the samples were SHT and quenched at the same time leaving only the other conditions, such as natural and artificial aging time, as variables as shown in Fig. 2. An optical microscope and a scanning electronic microscope (SEM) were used to examine the microstructure and fractographs samples under different heat treatment conditions.

The field of study and validity of the experiment are defined by considering the possible limits from the variation factors, the proposed test bench and especially the machine tool used. The choice of field of study is also constrained by combinations of levels impossible. During the construction of the design matrix, the boundaries of this area were chosen as wide as possible. The levels are the subject of compromise between two boundaries:

- If levels are too close to each other, they may not highlight the effect of factors.

- If levels are too far apart, the linearity assumption is less realistic and it may also lead to combinations of factors unworkable in practice.

Three levels of cutting speed and feed rate were tested in combination with three levels of lubricating modes and five

Table 2 Drilling process parameters

\begin{tabular}{|c|c|c|c|c|c|c|}
\hline Variable parameter & Low limit & & Intermediate & & High limit & Levels \\
\hline A: Cutting speed $(\mathrm{m} / \mathrm{min})$ & 60 & 200 & \multirow{5}{*}{$\mathrm{T}_{1}$} & \multirow{5}{*}{$\mathrm{T} 6_{2}$} & 320 & 3 \\
\hline B: Feed rate $(\mathrm{mm} / \mathrm{rev})$ & 0.015 & 0.15 & & & 0.35 & 3 \\
\hline $\mathrm{C}:$ Heat treatment & T0 & $\mathrm{T} 4$ & & & $\mathrm{~T} 7$ & 5 \\
\hline D: Cutting fluid & Dry & Mist & & & Wet & 3 \\
\hline Workpiece materials & \multicolumn{3}{|c|}{ A356 aluminum casting alloy } & & & \\
\hline
\end{tabular}

Table 3 Silicon particle measurements for the A356 cast alloys

\begin{tabular}{|c|c|c|c|c|c|c|c|c|}
\hline \multirow[b]{2}{*}{ Alloy (conditions) } & \multicolumn{2}{|c|}{ Area, $\mu \mathbf{m}^{2}$} & \multicolumn{2}{|c|}{ Length, $\mu \mathrm{m}$} & \multicolumn{2}{|c|}{$\begin{array}{c}\text { Roundness } \\
\text { ratio, \% }\end{array}$} & \multicolumn{2}{|c|}{ Aspect ratio } \\
\hline & Av. & SD & Av. & SD & Av. & SD & Av. & SD \\
\hline A356-T0 (non-modified) & 76.7 & 71.5 & 21.6 & 16.3 & 28.4 & 21.8 & 3.52 & 4.54 \\
\hline A356 (Sr-modified) & 5.18 & 3.21 & 3.05 & 2.16 & 46.0 & 19.2 & 2.11 & 2.14 \\
\hline A356-T4 (non-modified/SHT, 10 h) & 7.79 & 6.36 & 3.6 & 2.25 & 63.1 & 18.5 & 2.46 & 11.61 \\
\hline
\end{tabular}




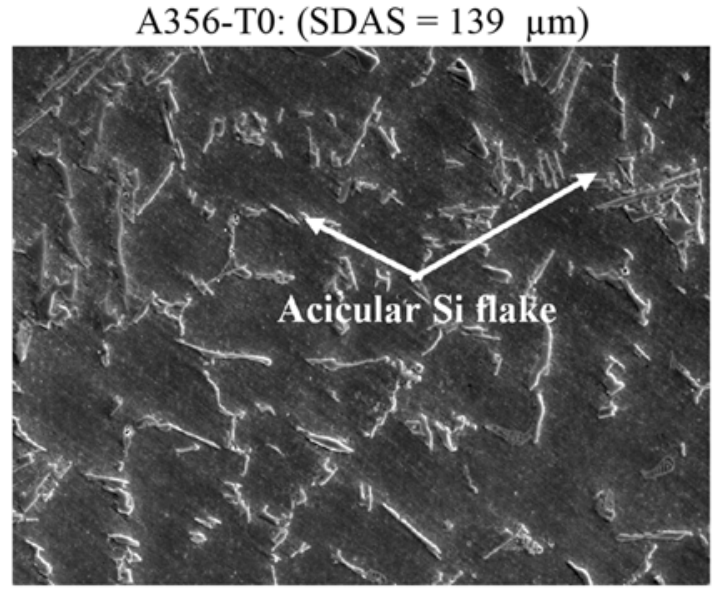

(a)

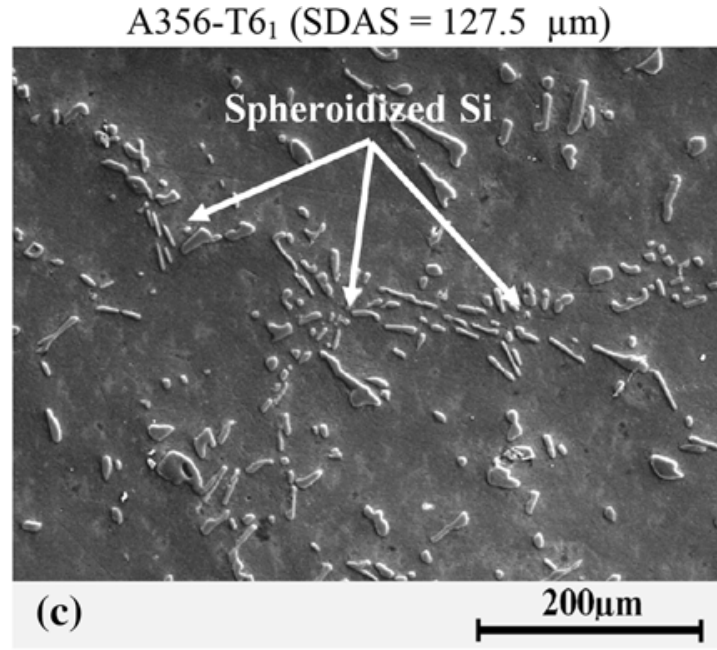

$\mathrm{A} 356-\mathrm{T}_{2}(\mathrm{SDAS}=124 \mu \mathrm{m})$

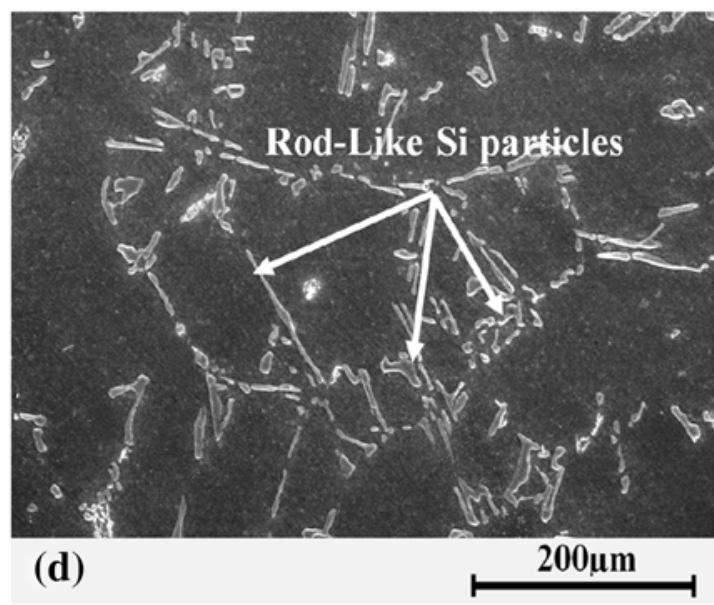

$\mathrm{A} 356-\mathrm{T} 7(\mathrm{SDAS}=120 \mu \mathrm{m})$

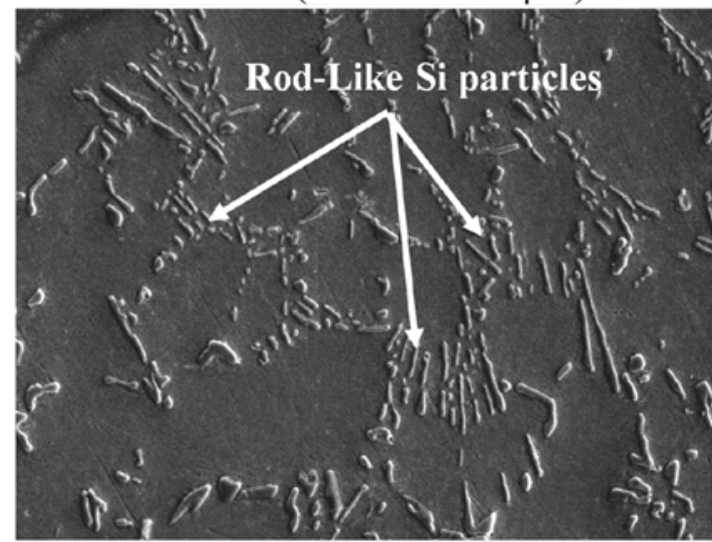

(e)
$200 \mu \mathrm{m}$

Fig. 3 SEM microscope image of an A356 aluminum alloy in (a) T0 as-received, (b) T4, (c) T61, (d) T62, and (e) T7 conditions

different heat treatments. To understand dust emission as a function of different factors and cutting parameters mentioned above and possible interactions between these input parameters, a full factorial design was used to build the matrix of experiments. The total mass concentration of dust emission representing the total mass per unit volume was computed from the particle number concentration and used as output responses. A total 135 experiments were performed. The factors studied and their levels are summarized in Table 2. 


\section{Results}

\subsection{Microstructure}

The modification is usually carried out by adding $\mathrm{Sr}$ as a 'modifier' to alloy melt. Modification of silicon particles can also be produced using other methods, e.g., a high cooling rate, solution heat treatment, or thermal treatment. In this study, the solution heat treatment was applied as alternative method because the solution treatment directly affects the silicon particles and produces spheroidized silicon particles. Thus, it will have an effect on the mechanical properties of Al-Si alloys. Table 3 shows the silicon particle measurements of A356 cast alloys in the non-modified (T0), Sr-modified, and SHT conditions (T4). As can be seen from this table, the effect of $\mathrm{Sr}$-modification in Si particle characteristics is almost the same influence of SHT; moreover, the latter has a significant effect on the roundness ratio whereas the roundness ratio increases from $28.4 \%$ in the non-modified condition to 46 and $63.1 \%$ in the $\mathrm{Sr}-$ modification and SHT conditions, respectively. The corresponding data (see Table 3) on the average particle area, particle length, and aspect ratio, respectively, show a decrease from $76.7 \mu \mathrm{m}^{2}, 21.60 \mu \mathrm{m}$, and 3.52 in the A356-T0 alloy to $7.79 \mu \mathrm{m}^{2}, 3.60 \mu \mathrm{m}$, and 2.46 in the A356-T4 alloy.

Figure 3(a)-(e) depicts SEM images showing the eutectic Si particle characteristics observed in as-cast-T0, SHT-T4, peek aged-T $6_{1}$, peek aged-T6 $6_{2}$, and stabilized/over aged-T7 samples

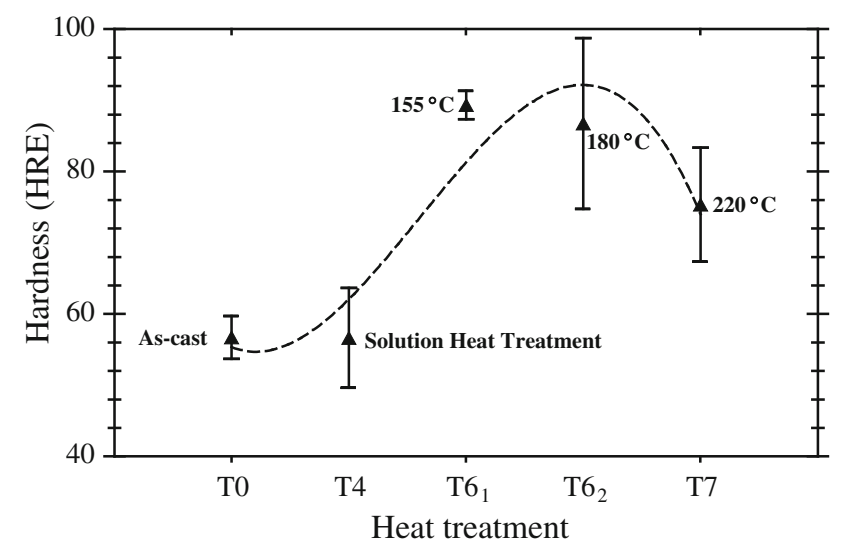

Fig. 4 Hardness values result in the heat treatment conditions of A356 cast alloys. In the as-cast conditions, A356-T0, the Si particles were platelet-like shaped, as shown in Fig. 3(a). Applying the solution treatment at $540{ }^{\circ} \mathrm{C}$ on the as-cast sample results in the acicular Si particles, which undergo "necking"; followed by fragmentation, as can be seen in Fig. 3(b) for a sample which has been SHT for $10 \mathrm{~h}$. Considering the various stages of the solution treatment as a whole, it can be seen that the three stages of fragmentation, spheroidization, and coarsening can occur together, as well, in the same microstructure, depending upon the variety of Si particle sizes present in the ascast structure. Thus, at any time during the solution treatment process, while some longer particles may undergo fragmentation, other smaller Si particles may become spheroidized, and those that are already spheroidized could start coarsening.

It is also observed that, both A356-T4 and A356-T6 treatments produce almost the same morphology of Si particles, as can clearly be seen in Fig. 3(b) and (c). When the aging temperature increased to 180 and $220{ }^{\circ} \mathrm{C}$, producing $\mathrm{T}_{2}$ and $\mathrm{T} 7$ conditions, respectively, the morphology of $\mathrm{Si}$ particles marked the start of the coarsening process, as shown in Fig. 3(d) and (e). It has been reported that the A356-T6 2 and T7 heat-treated specimens have dendritic microstructures with a rod-like eutectic phase rich in $\mathrm{Si}$ and $\mathrm{Mg}(\operatorname{Ref} 22)$. The particles size of silicon contributed $7 \%$ of the total surface area of the A356 alloy. During aging treatment, $\mathrm{Si}$ and $\mathrm{Mg}_{2} \mathrm{Si}$ phase precipitation occurred in the saturated solid solution of $\alpha(\mathrm{Al})$ according to the sequence in the Al-Mg-Si alloys. A needleshaped $\mathrm{Mg}_{2} \mathrm{Si}$ precipitation was observed, with length of about $0.5 \mu \mathrm{m}$ and less than $50 \mathrm{~nm}$ in width, and the silicon precipitates were mainly distributed in $\alpha(\mathrm{Al})$ dendrites (Ref 23). Because of their small size, these precipitations could not be observed by SEM in this study. However, hardness measurements were done to evaluate the changes in the aluminum matrix properties due to the heat treatment.

The SDAS is an important parameter that controls the alloy tensile properties. The smaller the dendrite cell size, the higher the tensile properties. A high cooling rate which results in a small dendrite arm spacing can improve the tensile properties of A356 alloy. Many studies (Ref 24-26) have pointed out that the SDAS is basically controlled by the cooling rate, since the cooling rate dictates the speed at which mass diffusion occurs. It should be mentioned here that The SDAS measurements reveal that the heat treatment has slightly effect on the SDAS of non-modified A356 cast alloy, as provided in Fig. 3.
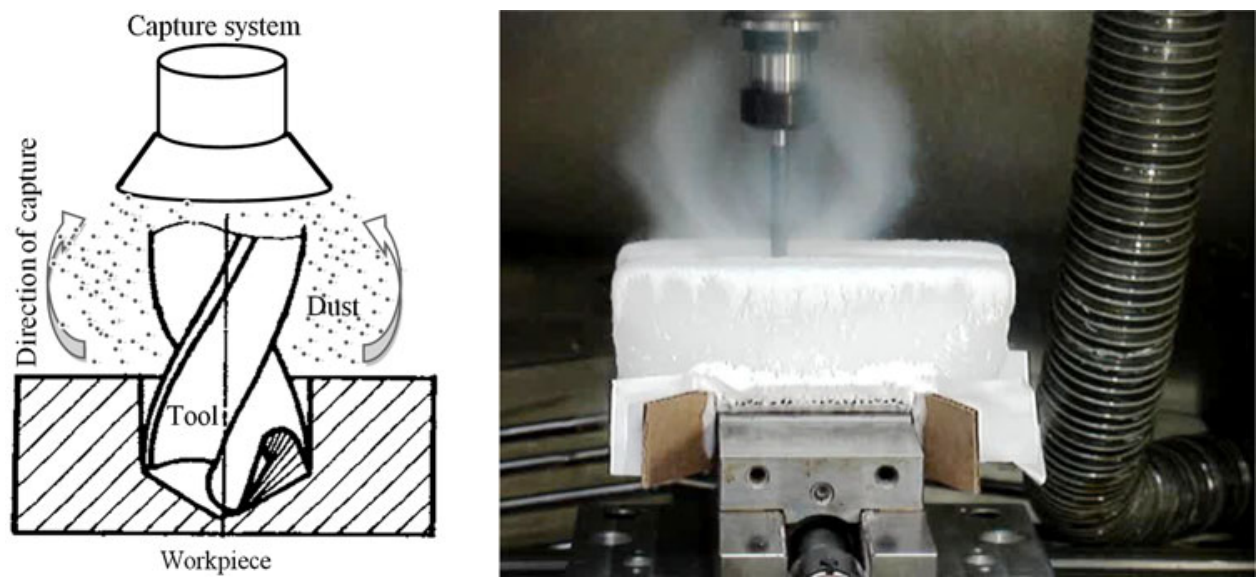

Fig. 5 Direction taken by the particles emitted during dry drilling 
Figure 4 summarizes the hardness measurement which was done on the A356 aluminum alloy. The hardness measurements reveal that the peak hardness value varies between $85 \mathrm{HRE}$ and 90 HRE. Hence, it is believed that aging at $155^{\circ} \mathrm{C}$ for $5 \mathrm{~h}$ produces almost the same precipitation hardening as aging at $180{ }^{\circ} \mathrm{C}$ for $5 \mathrm{~h}$. Then hardness then tends to decrease upon further aging. The variations of hardness when exposed to different aging temperatures are correlated with the $\mathrm{Mg}_{2} \mathrm{Si}$ precipitation in which the hardness increases with the evolution of coherency of $\mathrm{Mg}_{2} \mathrm{Si}$ precipitation (Ref 27).

\subsection{Dust Emission}

Non-coated high speed steel twist drills were used in the drilling process. The helical flutes do not cut, but rather, are used to evacuate the chips from the drilled hole. These helical flutes also provide an escape direction for the dust produced during cutting, as shown in Fig. 5. During the drilling process, the dusts are generated around the drill bit. After the particles are generated, they are projected outwardly from the cutting area, and remain suspended in the air for extended periods. The distance traveled and the direction taken by these particles depend on the size of the particles, the shape, and other parameters (temperature, pressure, humidity, etc.). It was seen that the fine particles behave like a projectile, and that ultrafine particles follow the air flow generated by the tool rotation. Finally, emissions of fine and ultrafine particles in machining are affected by cutting conditions and the cutting process.

Figure 6 shows typical dust emission results as a function of the time obtained using DustTrak ${ }^{\mathrm{TM}}$.

A good sampling requires an appropriate capture system and a proper examination of the process used along the spindle for drilling. The dust samples were collected using MOUDI stages through cascade impaction to classify the particles. Observations with the scanning electron microscope showed the particles to be heterogeneous and agglomerate (Fig. 7a). This morphology depends on the nature of the material and the mechanism that produced it. Similarly, the agglomeration of particles does not lead to spherical particles. Chemical analysis of microscopic particles was performed using the scanning

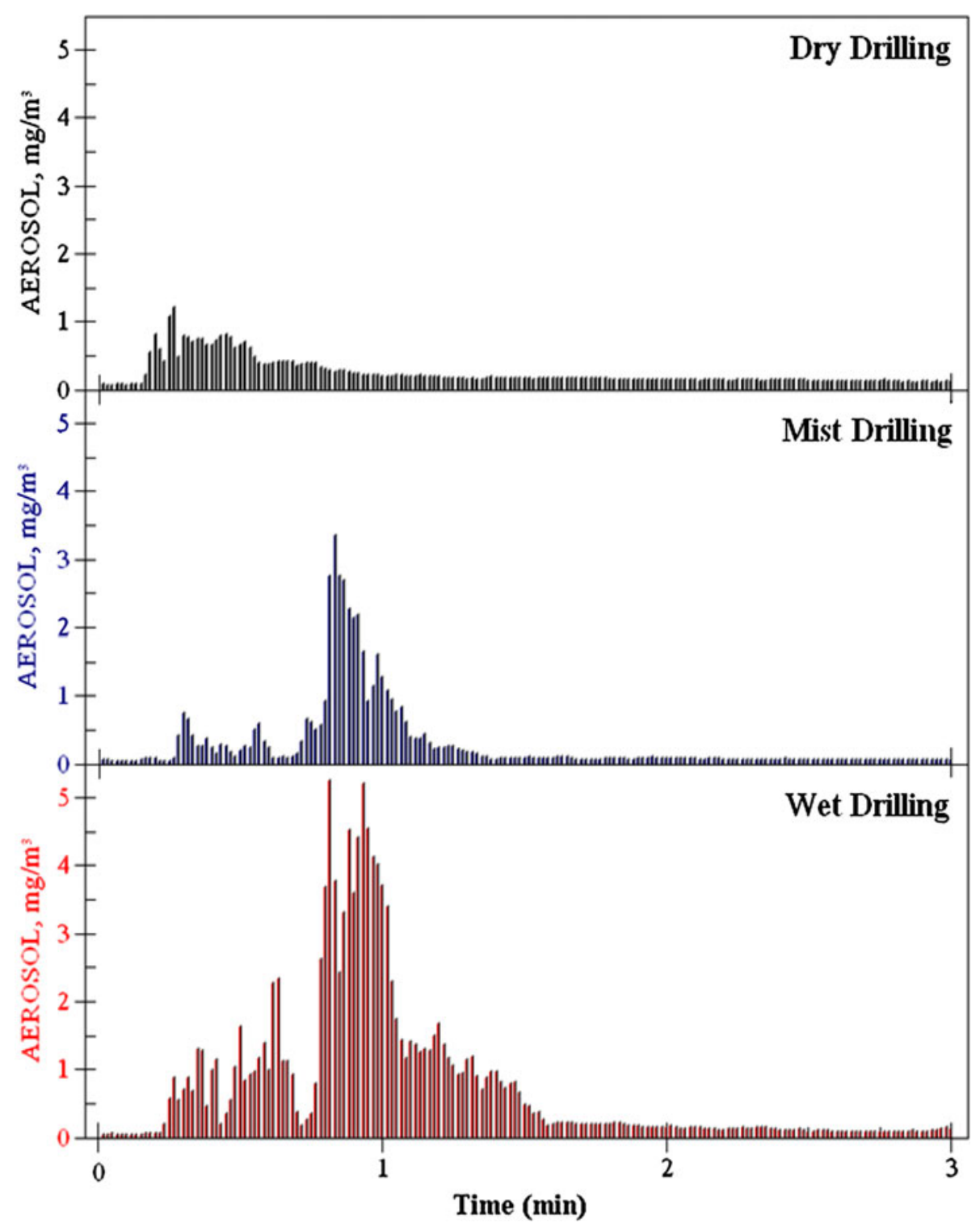

Fig. 6 Mass concentrations for A356-T61 at $200 \mathrm{~m} / \mathrm{min}$ cutting speed, and $0.15 \mathrm{~mm} / \mathrm{rev}$ feed rate (PM2.5) 
electron microscope. Energy dispersive spectrometer (EDS) micro-analysis is performed by measuring the energy and intensity distribution of $\mathrm{x}$-ray signals generated by a focused electron beam on the dust particles. With the attachment of the energy dispersive spectrometer, the elemental composition of particles was obtained (Fig. 7b).

Figure 8(a) shows the effect of different heat treatment on the dust emission with various cutting speed and feed rate during dry machining of A356 aluminum alloys. The experimental results reveal that the A356-T6 $6_{1}$ aluminum alloy in peak aging condition produces more dust emission than other alloys since the A356-T6 aluminum alloy generates $32 \%$ of dust more than the alloy A356$\mathrm{T} 7$ alloy in dry condition. While the A356-T4 in SHT conditions was produced moderate level of dust emission. Generally, it is also observed that aging at low temperature, $155^{\circ} \mathrm{C}$, was observed to produce the greatest level of the dust emission while the aging at higher temperatures, 180 and $220{ }^{\circ} \mathrm{C}$, respectively, are accompanied by a reduction in the dust emission level.

Figure 8(d) shows the importance of the cutting fluid effect on dust emission. This observation confirms that the particle emission concentration is higher for mist and wet machining than for dry machining shown previously in Fig. 6. It should be noted that the wet and mist machining aerosols consist of both fluid and metallic particles. The aerosol produced in wet and mist conditions are more pronounced than the metallic particles. To emphasize the effect of heat treatments on the material properties and its effects on the dust emission thus, the discussion will be focused on dry conditions.

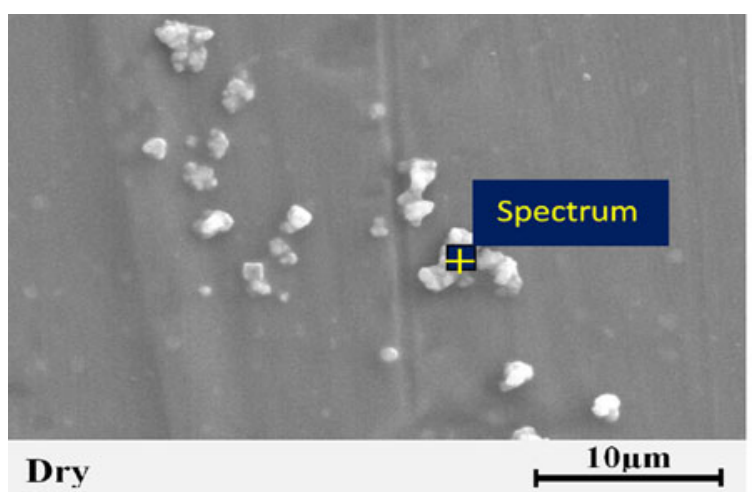

(a)

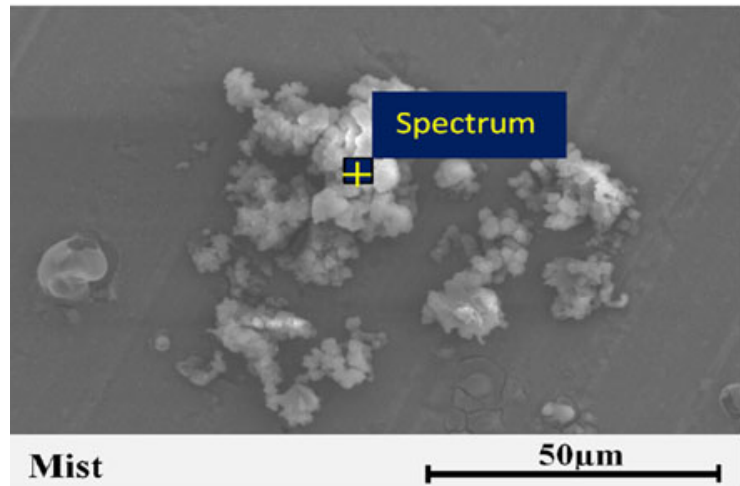

(a)

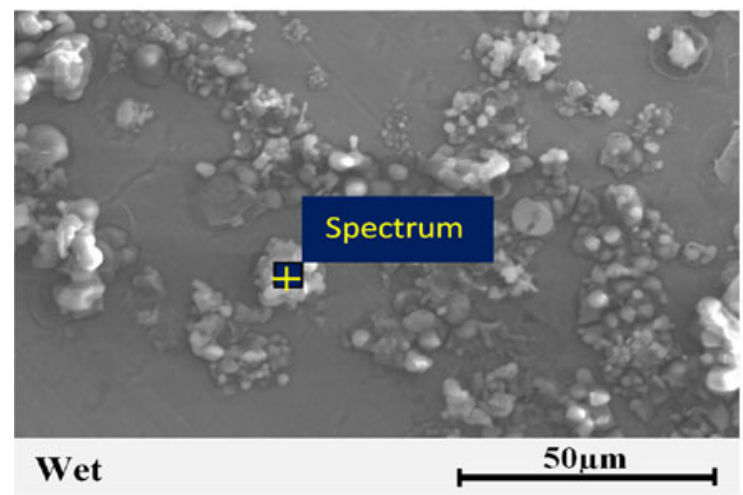

(a)

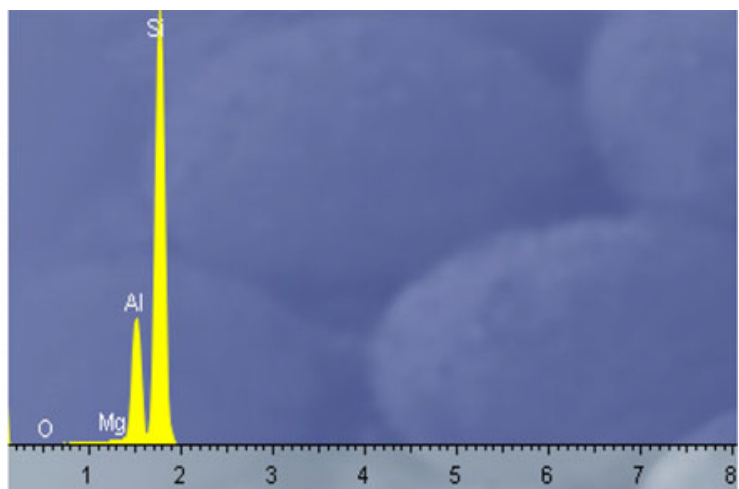

(b)

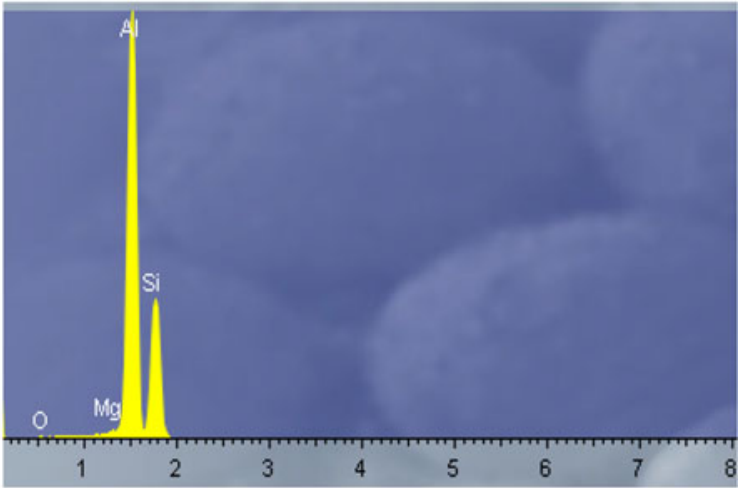

(b)

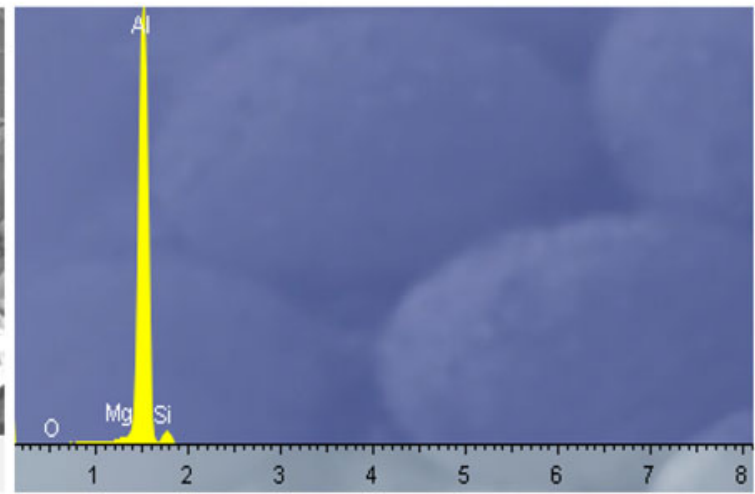

(b)

Fig. 7 SEM images and chemical analysis of particles emitted during machining of A356-T61 alloy at cutting speed of $200 \mathrm{~m} / \mathrm{min}$ and feed rate of $0.15 \mathrm{~mm} / \mathrm{rev}$ 

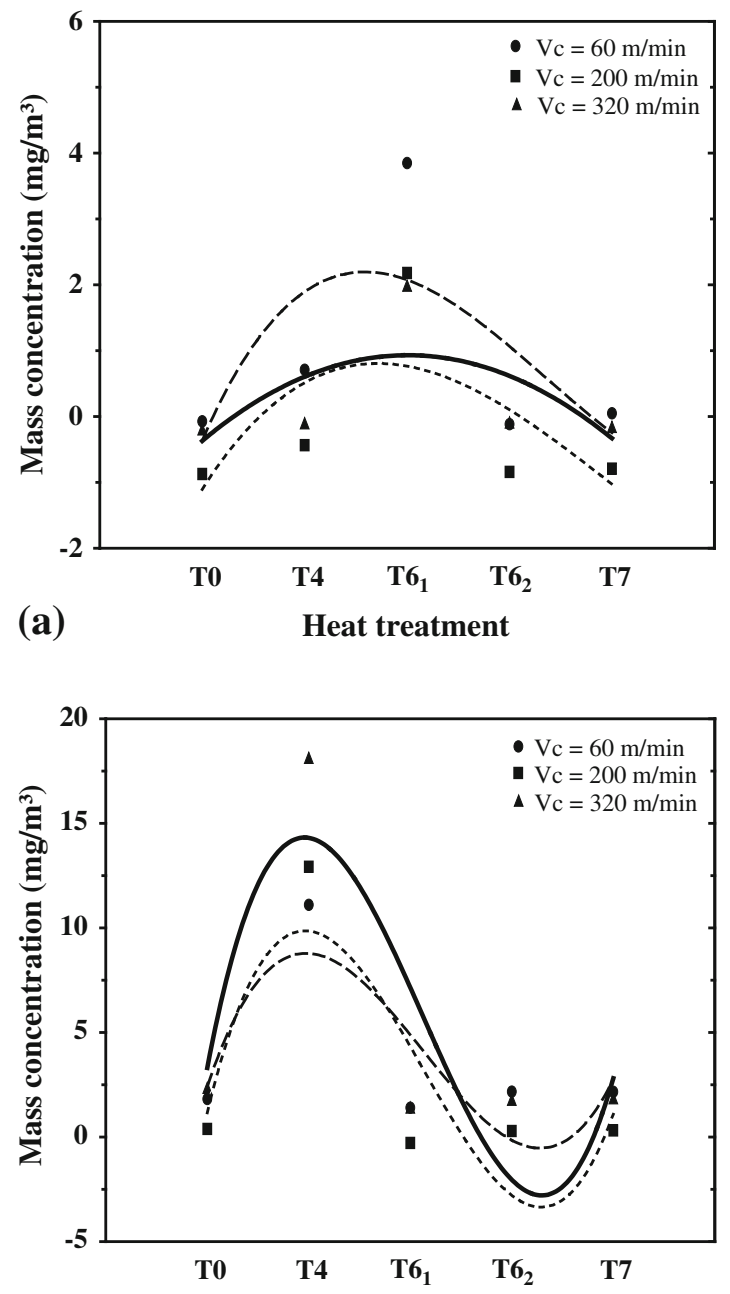

(c)
Heat treatment
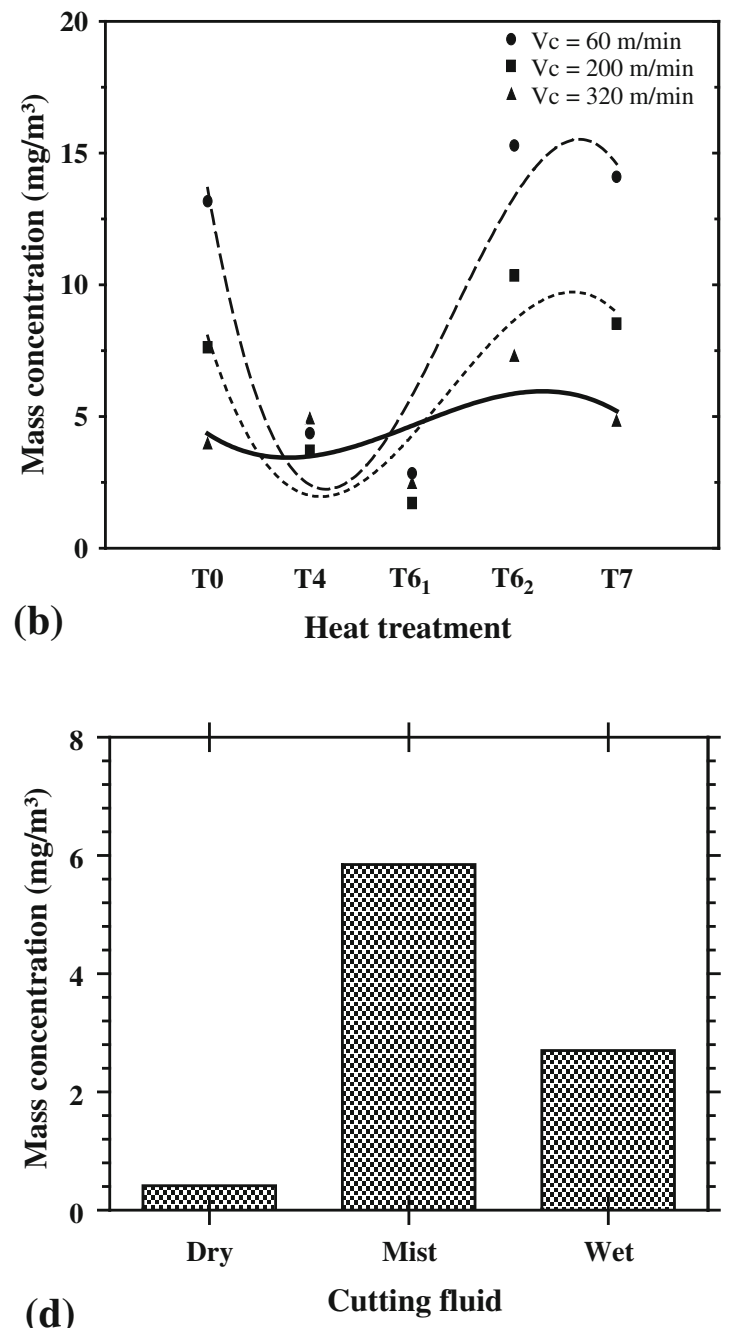

Fig. 8 Influence of the heat treatments and cutting fluid on the dust emission during (a) Dry, (b) Mist, and (c) Wet process drilling of the A356 aluminum alloy

It is interesting to note that the trend of the cutting forces with different heat treatment conditions, as clearly shown in Fig. 9, is similar to those observed with dust emission concentration results at same cutting conditions. It was observed that the cutting forces values during machining the $\mathrm{T} 4, \mathrm{~T} 6_{1}$, and $\mathrm{T} 6_{2}$ work pieces are higher than those observed when machining the $\mathrm{T} 0$ and $\mathrm{T} 7$ workpiece at cutting speeds between 60 and $320 \mathrm{~m} / \mathrm{min}$. A reduction of cutting forces with increasing cutting speed can be attributed to the reduction of friction at the tool-chip interface, as a result of thermal softening of the workpiece before it enters the cutting zone. Higher friction at the tool-chip interface during machining of the A356-T6 $6_{1}$ workpiece also results in higher dust emission in comparison with machining of the A356-T4 and T7 workpiece.

\subsection{Statistical Analysis of Data}

3.3.1 Direct Factors Effects on Dust Generation. Figure 10 presents the direct effects diagram in terms of mass concentration of particles generated versus the cutting parameters, heat treatment, and lubrication modes. The direct effects diagram of the particles mass generated highlights the important factors, namely, the heat treatments and the cutting fluid. It was observed that the aerosol particles emitted during mist and wet processes are more prominent than the metallic particles generated from machining operations. Therefore, the cutting fluid influence overlaps the effect of material properties on dust generation during the cutting process. It is observed that the particle emission concentration is higher (about 5 times) for wet and mist machining than for dry machining. It was also found that dust emission decreases with increases in the cutting speed and feed rate. The lowest level of dust emissions were found during machining at a cutting speed and feed rate of $200 \mathrm{~m} / \mathrm{min}$ and $0.35 \mathrm{~mm} / \mathrm{rev}$, respectively.

3.3.2 Pareto Diagram. The Pareto diagram in Fig. 11 compares the relative importance and statistical significance of main factors and interaction effects between factors of the experiments which was performed. The Pareto chart indicates the statistical significance level at a confidence level of $95 \%$. The Pareto diagram identifies the influential factors in order of decreasing contribution, in which the predominance effect corresponds to the interaction effect of the cutting fluid and heat treatment $(\mathrm{CD})$ for the response mass concentration. Next in significance are the cutting fluid factor (D) and heat treatment factor (C), which represent more than $90 \%$ of the variations found in the response. The contribution by the factor feed rate 


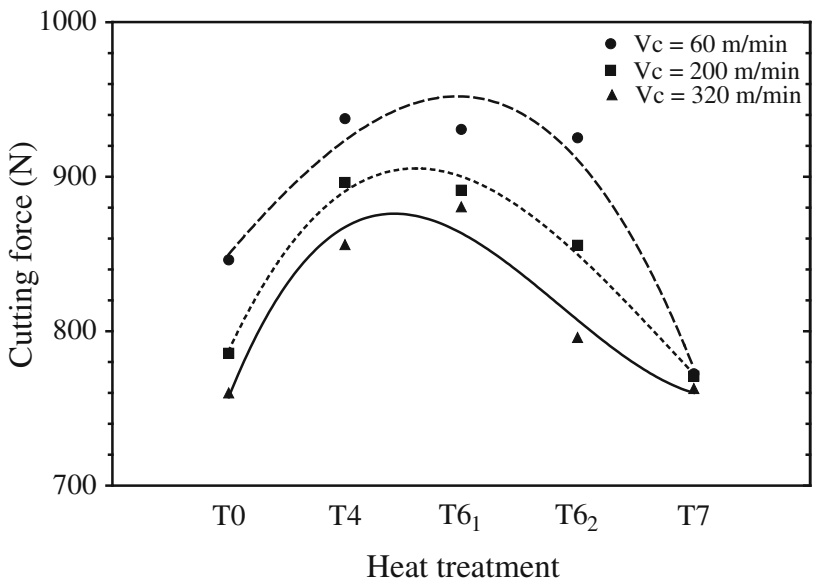

Fig. 9 Influence of the heat treatments on the cutting force during the dry drilling of the A356 aluminum alloy

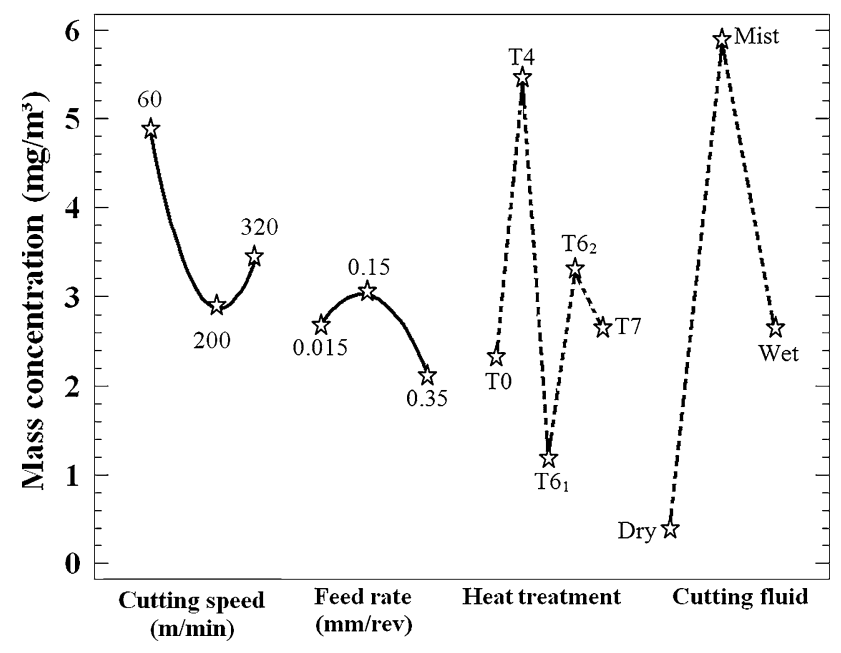

Fig. 10 Direct factors effects on mass concentration of particles generated

is slight as its influence is small compared to other factors. Therefore, the cutting fluid and heat treatment factors are strongly controlled the dust emission level. Moreover, the interaction between the cutting speed, feed rate, cutting fluid, and heat treatment factors is highlighted in the Pareto diagram. The effects of these interactions are also significant than the rest of the factors.

3.3.3 Response Surfaces. The interaction effects of the cutting speed and the feed rate with different heat treatment regimens applied on the studied alloys were presented in Fig. 12(a)-(e). For the A356-T0 aluminum alloy, increasing both feed rate and cutting speed decreases the dust generation level (Fig. 12a). The lowest value of the dust generation was obtained for the high feed rate and cutting speed. For the aluminum alloys A356-T6 1 and A356-T7, the influence of cutting speed on the dust generation remains quietly similar to the aluminum alloy A356-T0 except, the influence of the feed rate presents a maximum for the intermediate value of feed rate. In general, it can be moreover reported that also the increase of the cutting speed and feed rate can contribute to decrease the dust generation. For the A356-T6 2 aluminum alloy, the smallest value of the dust generation was obtained for the lower feed and

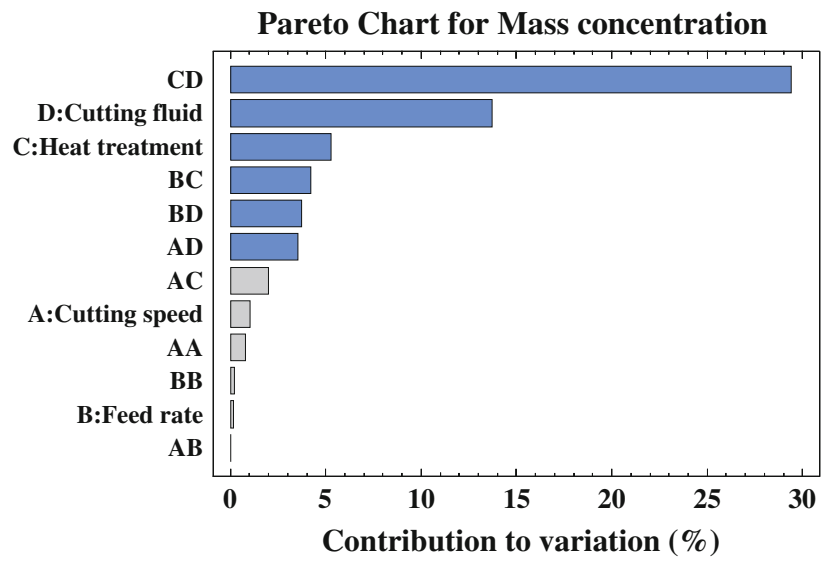

Fig. 11 Pareto diagram for mass concentration

the high cutting speed. Conversely, for the A356-T4 aluminum alloy, there is a wide variation. Eventually, the response surface identified a region of the experimental field in which the dust emission is maximal (to be avoided). This maximum is given by the combination of a critical cutting speed and feed rate. The smaller value of the dust generation was obtained for the lower feed and the intermediate value of cutting speed.

\section{Discussion}

The properties of aluminum casting alloys can be improved through the appropriate control of several metallurgical factors involved in the production of these castings (Ref 28). Aging treatment is usually applied to improve the strength and hardness of the castings. Aging temperature and aging time are the two variables which control the characteristics of the phases precipitated during the aging treatment, and they ultimately also control the mechanical and machinability properties of the alloys. The tensile mechanical properties of A356 alloys are given in Table 4. The tensile strength and fracture elongation can reach maximum values with $\mathrm{T} 6_{1}$ and $\mathrm{T} 6_{2}$ conditions, respectively.

With the object of evaluating the dust emission behavior of non-modified A356 alloys, the individual or combined effect of the application of solution heat treatment and aging treatment on such behavior may be analyzed based on the fracture mechanism of the alloys under investigation. The fracture mechanism of A356 alloys are strongly regulated by the morphology and the size of both eutectic $\mathrm{Si}$ and $\mathrm{Mg}_{2} \mathrm{Si}$ phases. Figure 13(a) and (b) shows the SEM images of the fracture surface of A356-T6 $6_{1}$ alloys aged at $155^{\circ} \mathrm{C}$ for $5 \mathrm{~h}$; a mixed fracture mode may be observed in this case illustrating brittle/ ductile features. The cleavage cracking of Si particles inside the dimples will be seen in Fig. 13(a) which shows the occurrence of the fracture, known as cellular fracture, in a two-phase region (Ref 29, 30). In this latter type of fracture, two different phases coexist and each one has its own mode of fracture. The phases in this specific case are the hard Si particles and the ductile $\alpha$ Al-matrix. The hard silicon particles were observed to fracture in a brittle manner through several cleavage cracks, as may be seen in Fig. 13(a), whereas the $\alpha$-Al-matrix displays a ductile fracture mode within the formation of the oval-shaped dimples. Cleavage cracks are also shown in Fig. 13(b) indicating the 

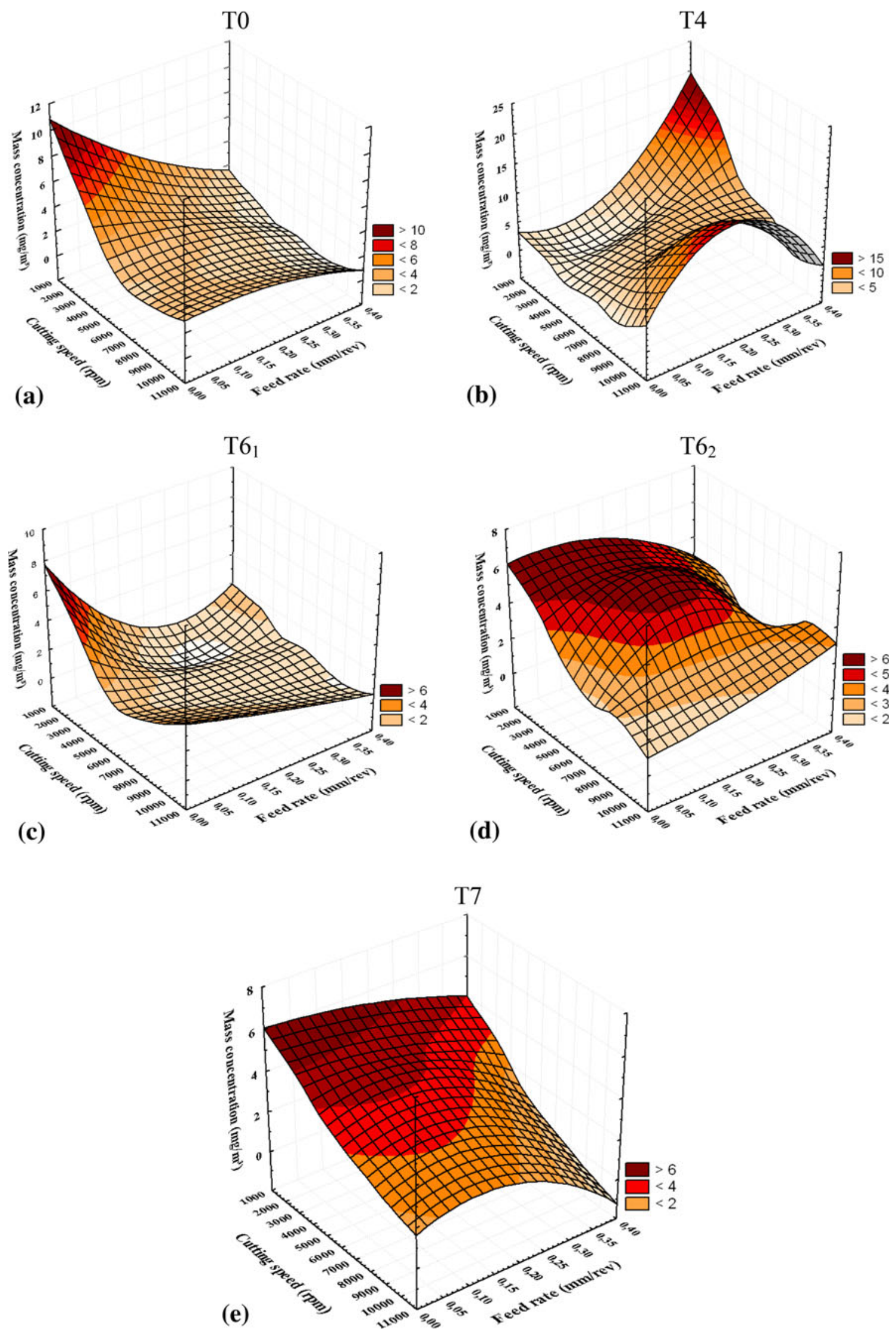

Fig. 12 Influence of the heat treatments (T0, T4, T61, T62, and T7), the cutting speed and the feed rate on the dust generation during the drilling of the A356 alloy 


\begin{tabular}{|c|c|c|c|c|c|}
\hline \multirow[b]{2}{*}{ Property } & \multicolumn{5}{|c|}{$\mathbf{A 3 5 6}$} \\
\hline & T0 & T4 & T6 $_{1}$ & $\mathbf{T 6}_{2}$ & $\mathbf{T 7}$ \\
\hline Tensile strength, $\sigma_{b} / \mathrm{MPa}$ & 150 & 170 & 234 & 220 & 200 \\
\hline Yield strength, $\sigma_{0.2} / \mathrm{MPa}$ & 88 & 105 & 205 & 175 & 165 \\
\hline Elongation, $\delta \%$ & 1.8 & 4.0 & 3.5 & 2.8 & 2.0 \\
\hline Hardness, HRE & 55 & 60 & 90 & 85 & 74 \\
\hline
\end{tabular}
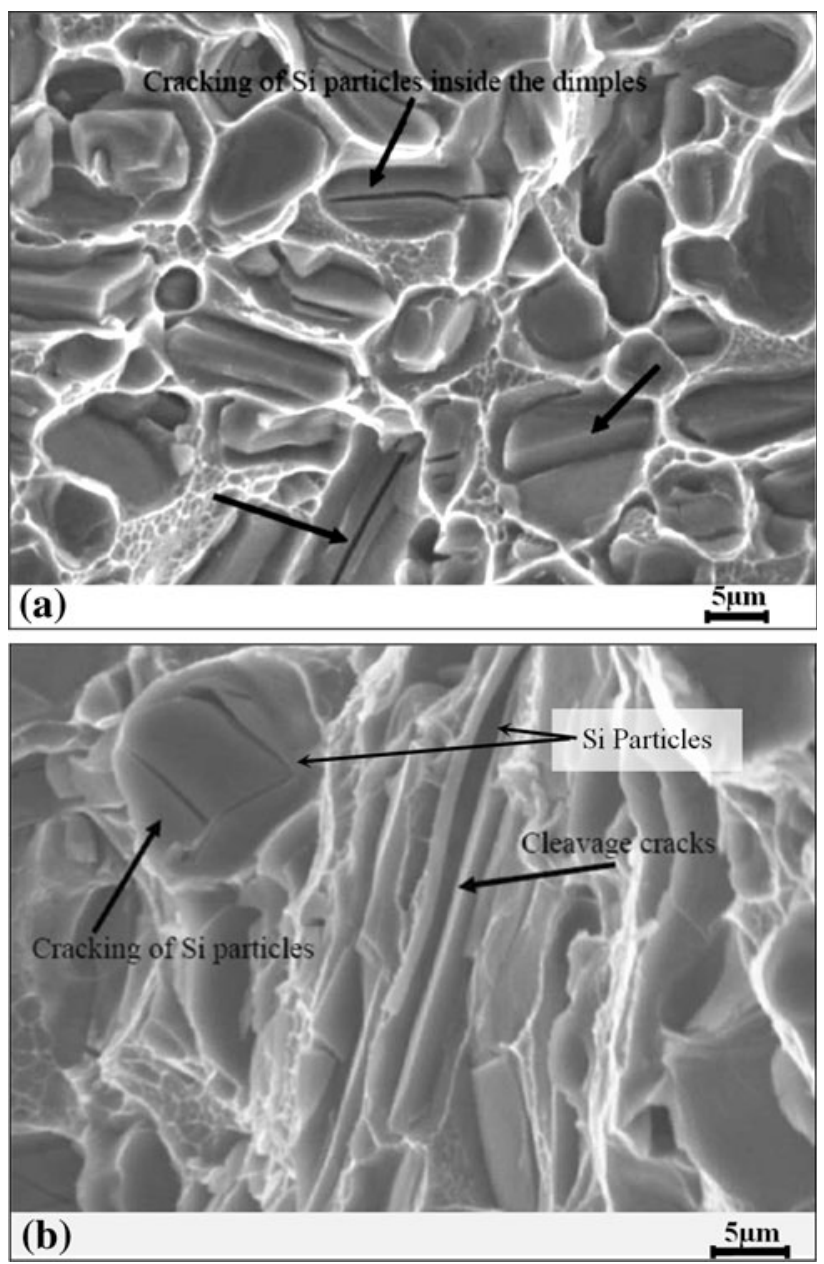

Fig. 13 SEM images of the fracture surface of the A356-T61 alloy casting (a) and (b) cleavage cracking which characterizes the mixed fracture mode observed upon aging at $155^{\circ} \mathrm{C}$ for $5 \mathrm{~h}$

brittle features observed at the fracture surface of the samples which were subjected to aging at a lower treatment temperature of $155^{\circ} \mathrm{C}$ for $5 \mathrm{~h}$.

In the other words, the highest level of dust emission was observed in peak aging conditions A356-T6 $6_{1}$ alloy may be explained based on the fact that dust emission is closely related to the hardness of the workpiece, as well as to the deformability of the matrix around the Si particles. Thus, when the workpiece made of the A356-T6 1 alloy is hard (i.e., high tensile properties), thereby resisting deformation, and the work material is also difficult to deform in the shear zone ahead of the cutting edge and on the tool surface in such a way that the Si particles are secured firmly in position. Consequently, the particles have a strongly abrasive action on the tool cutting
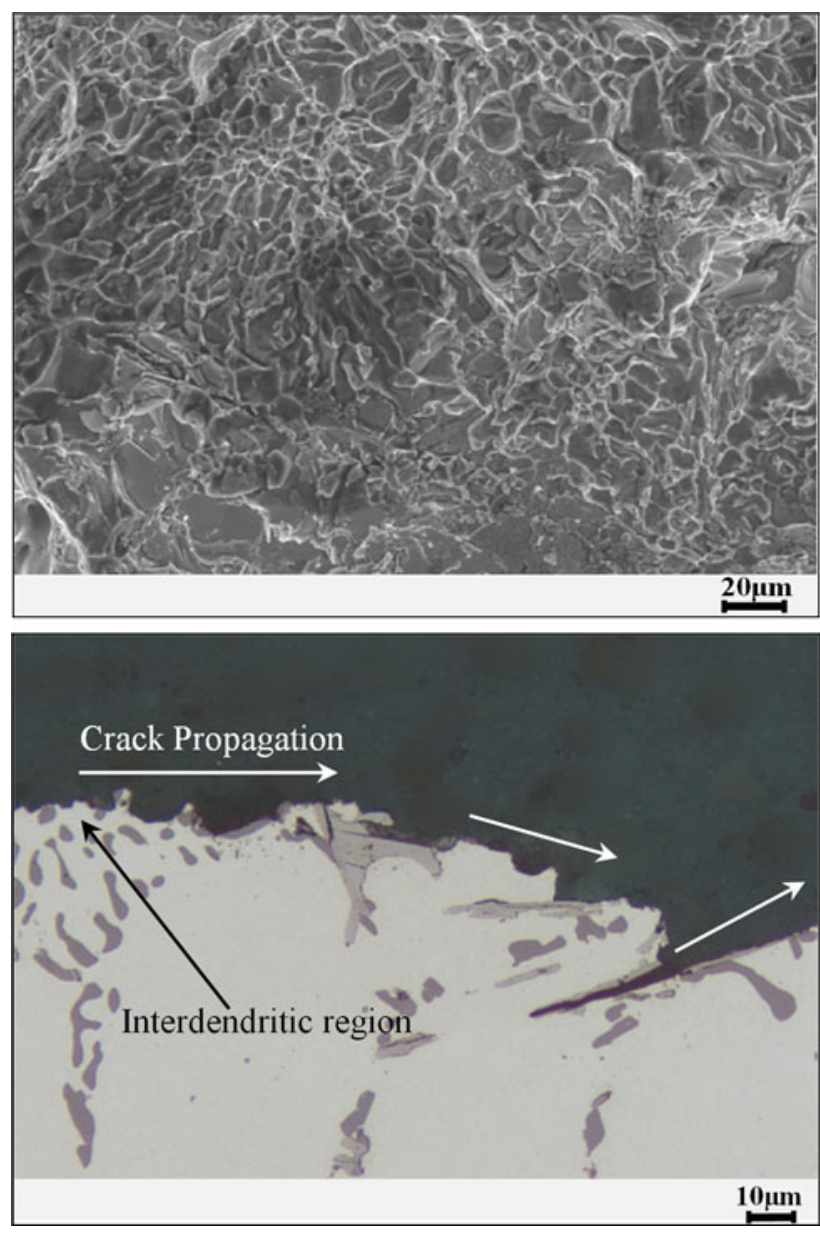

Fig. 14 SEM images of the fracture surface of the A356-T4 alloy casting show that deep shear dimples which are features of the ductile fracture mode observed upon SHT

edge resulting in a high cutting force as well as in a high level of dust emission level.

The results also show that the A356-T4 alloys produce moderate level of dust emission. The application of the solution heat treatment contributes significantly to further decreasing the number of crack initiation sites through the spheroidization of eutectic Si particles and the dissolution of the brittle $\mathrm{Mg}_{2} \mathrm{Si}$ phase. The fracture surface of non-modified A356-T0 alloy consisted of long Si particle with cracks at their interiors, while the application of solution heat treatment A356-T4 resulted in a dimple structure through the matrix. The fracture surface also shows separation of the $\alpha$-Al dendrites indicating that the fracture occurs primarily in the ductile mode, as may be seen clearly in Fig. 14. 

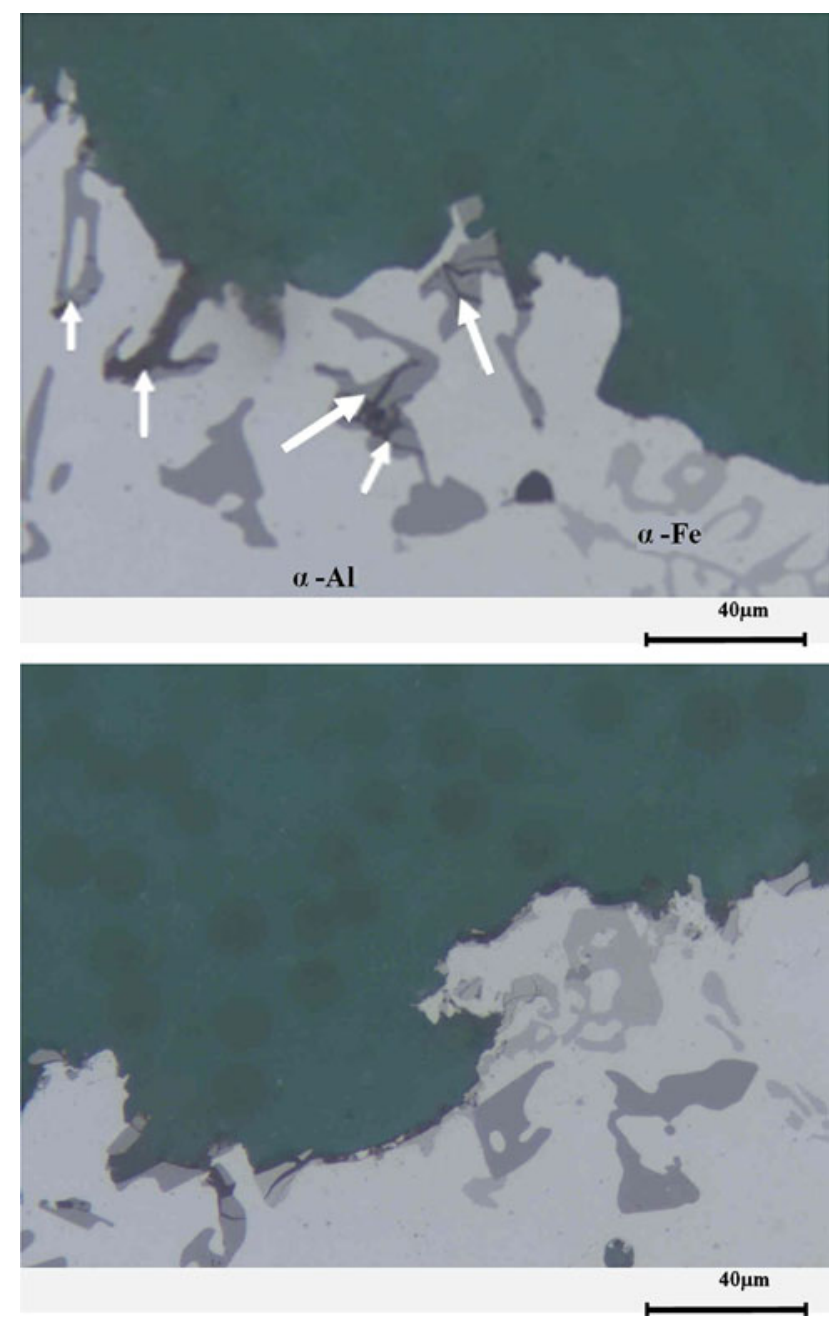

Fig. 15 Microstructure beneath the fracture surface of the A356-T0 alloy. White arrows indicate broken acicular Si particles

On the other hand, the A356-T0 in as-cast condition exhibit lowest level of dust emission in dry machining. This result explained in term of the non-modified acicular silicon structure, as shown previously in Fig. 3(a), provides an easy path for fracture, as shown in Fig. 15, resulting in decreases in the cutting force in turn decrease the dust emission during the machining of the A356-T0 alloy.

Chip formation depends on the nature of the workpiece material and its heat treatment conditions. Dust emission is influenced by the chip formation mechanism and by the nature of the surface generated by the chip during its formation. It was found that the increase in the chip fragmentation is a significant indicator of its brittleness. The more brittle the fracture, the less both of the plastic deformation and microscopic-scale friction, and thus the generation of dust will be decreased. During drilling processes, the chip undergoes a major deformation on its outer surface during its formation. The outer faces experiences shear stresses, which involve the formation of small torn surfaces that rub against each other as they are formed in turn generates dust particles. Figure 16(a) and (b) shows SEM image of chip obtained during drilling A356-T0; the outside surface of this chip exhibits many small cracks, which is a characteristic of brittle fracture A356-T0 cast alloys. By contrast, the chip formation of A356-T4 which is more ductile, as shown in Fig. 16(c) and (d). The deformation and the friction on this surface are higher than in the case for brittle materials. The formations of microcracks in the brittle materials decrease the microfriction and in turn, dust emission. The chips produced by machining the peak material A356- $\mathrm{T}_{1}$ reveal no systematic segmentation behavior. It was observed the fragmentation bands are denser and strongly crushed against one another corresponding to maximum generation of dust as shown in Fig. 16(e) and (f), whereas the bands are more spaced in the case of over-aging A356-T7 materials which generate less dust emission as shown in Fig. 16(g) and (h).

\section{Conclusion}

This work has been investigated the dust emission during machining of A356 cast alloy with various heat treatments. The experimental results proves that the heat treatment parameters strongly controlling the metallic particles emission. The following conclusions may be formulated from experiments conducted with a view to studying the influence of A356-T0, A356-T4, A356- $6_{1}, \mathrm{~A} 356-\mathrm{T}_{2}$, and A356-T7 conditions as well as the effect of various lubrication modes including dry, mist, and wet process on the machinability in terms of particles emission of A356 cast alloys.

1. Artificial aging at low temperature of $155^{\circ} \mathrm{C}\left(\mathrm{A} 356-\mathrm{T} 6_{1}\right.$ conditions) was observed to generate the greatest level of the dust emission while the artificial aging at high temperature of $220{ }^{\circ} \mathrm{C}$ (A356-T7) is accompanied by significant reduction in the dust emission level. It was also observed that the A356-T0 alloy produces the same level of dust as that in the A356-T7; whereas the A356-T0 is accompanied with loss in the mechanical properties and also many problems in machining including high tendency to BUE formation and bad surface quality of produced surface.

2. The dust emission was found strongly controlled by the fracture surface nature of the heat-treated alloys. Thus, in the A356-T6 6 the dust emission is closely related to the hardness and deformability of the matrix around the $\mathrm{Si}$ particles. Consequently, the Si particles have a strongly abrasive friction action on the cutting tool resulting in high cutting force and high level of dust emission. Conversely, in the A356-T0 provides an easy path for crack and fracture resulting in decreases the cutting force and dust emission.

3. Chip formation depends on the nature of the workpiece material and its heat treatment conditions. Dust emission is influenced by the chip formation mechanism, brittle chips as A356-T0 and A356-T7 are submitted to a mechanism that support crack propagation and rupture, consequently reducing the generation of fine particles. On the other hand, ductile chips as A356-T4 and A356-T6, result in a high level of plastic deformation of the chip, which increases the microbands and generate more fine particles.

4. It was found that the concentration of particle emission is higher of about 5 times for wet and mist machining than for dry machining. It was observed that the aerosol particles emitted during mist and wet processes are more prominent than metallic particles generated from 


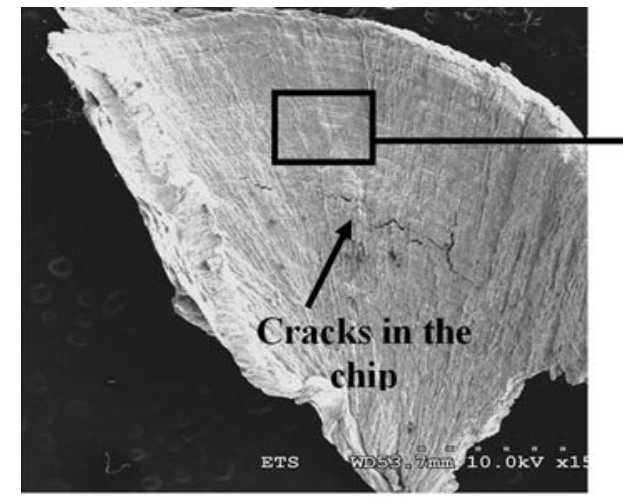

(a) A356-T0_X15

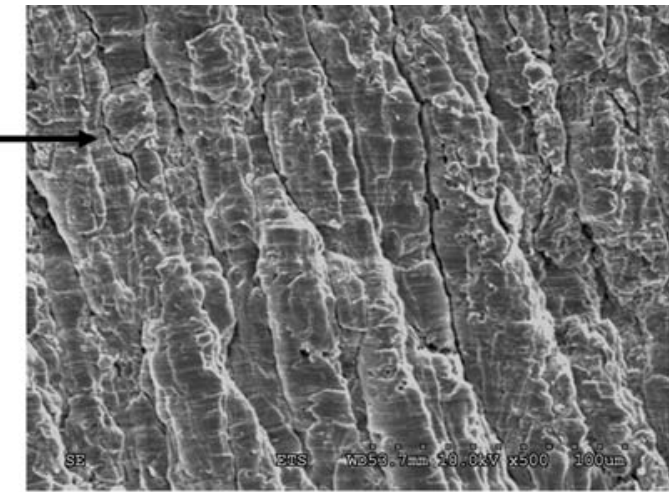

(b) A356-T0_X500

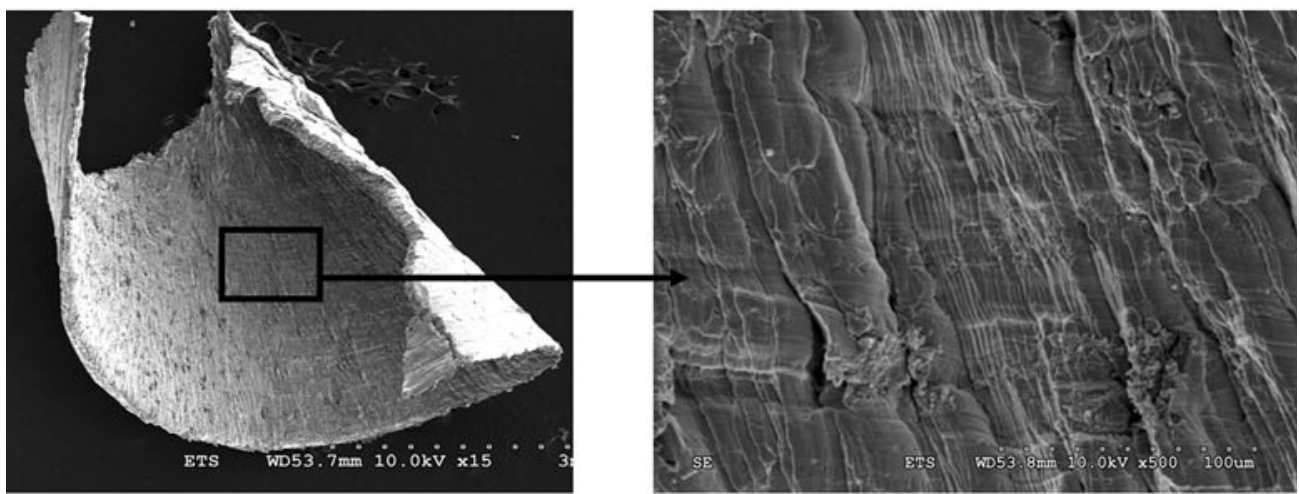

(c) A356-T4_X15

(d) A356-T4_X500

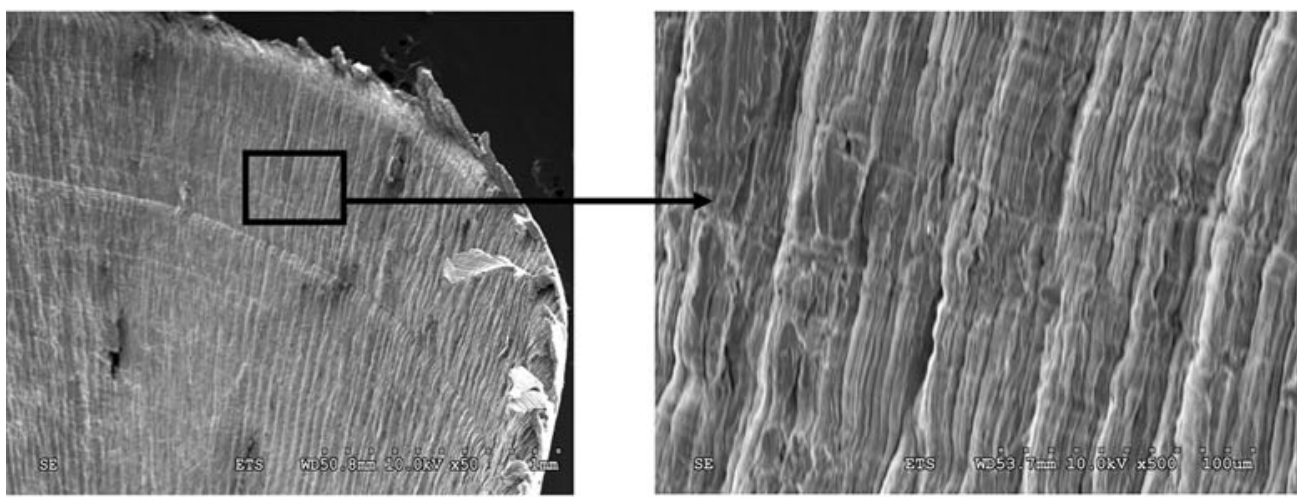

(e) A356-T61 X50

(f) A356-T61 X500

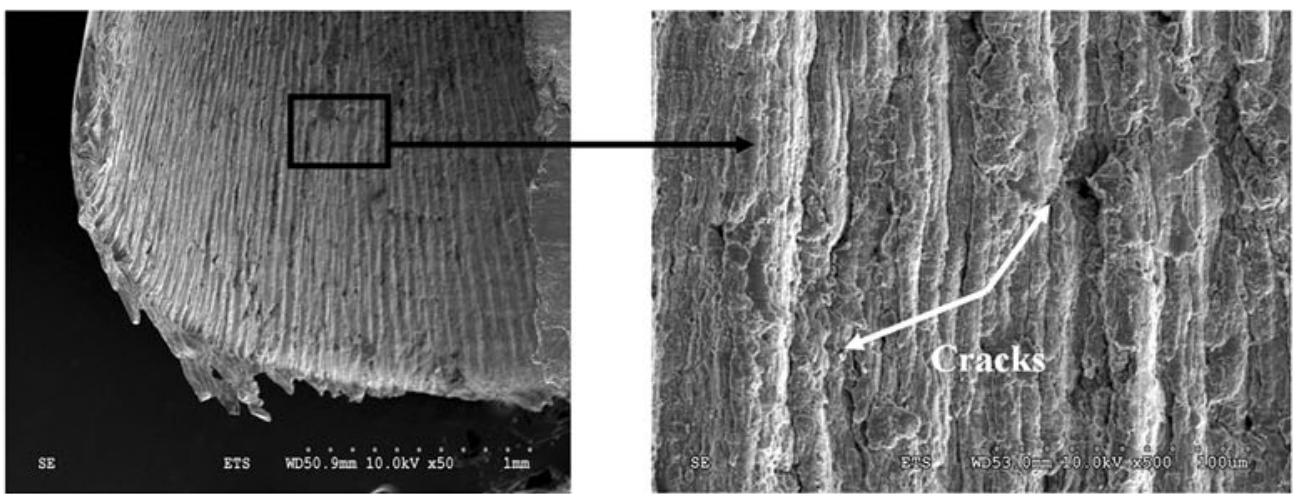

(g) A356-T7_X50

(h) A356-T7_X500

Fig. 16 SEM of the effect of heat treatment on the chip formation of A356 cast alloys 
machining operation. The lowest level of dust emissions were found during machining at cutting speed and feed rate of $200 \mathrm{~m} / \mathrm{min}$ and $0.35 \mathrm{~mm} / \mathrm{rev}$, respectively.

5. The strategies of the eliminating at the source can be carried out at three levels: the emissions, undesirable substances, and work practices. The work practices or production processes can be improved by applying methods that generate less dust. This examination indicates that the aging at higher temperatures is accompanied by a reduction in harmful dust emission, and ensures good parts quality.

\section{Acknowledgments}

The authors would like to acknowledge the support of IRSST, Aluminum Research Centre and ÉTS.

\section{Open Access}

This article is distributed under the terms of the Creative Commons Attribution License which permits any use, distribution, and reproduction in any medium, provided the original author(s) and the source are credited.

\section{References}

1. NIOSH, What You Need to Know About Occupational Exposure to Metalworking Fluids, DHHS (NIOSH) Publications, p 98-116, 1998

2. N.S.K. Reddy and P.V. Rao, Selection of an Optimal Parametric Combination for Achieving a Better Surface Finish in Dry Milling Using Genetic Algorithms, Int. J. Adv. Manuf. Technol., 2006, 28, p 463-473

3. M. Warmuzek, Aluminum-Silicon Casting Alloys: Atlas of Microfractographs, ASM International, Materials Park, 2004

4. Q. Wang and C.H. Caceres, Mg Effects on the Eutectic Structure and Tensile Properties of Al-Si-Mg Alloys, Materials Science Forum. Trans Tech Publ, p 159-164, 1997

5. M. Moustafa, F. Samuel, and H. Doty, Effect of Solution Heat Treatment and Additives on the Hardness, Tensile Properties and Fracture Behaviour of Al-Si (A413.1) Automotive Alloys, J. Mater. Sci., 2003, 38, p 4523-4534

6. E. Pan, J. Hu, and C. Fan, Solution-Treatment Conditions for Optimal Tensile Properties in A357 Alloy, AFS Trans., 1996, 104, p 1119-1132

7. S. Shivkumar, C. Keller, and D. Apelian, Aging Behavior in Cast AlSi-Mg Alloys, AFS Trans., 1990, 98, p 905-911

8. J. Sutherland, V. Kulur, N. King, and B. Von Turkovich, An Experimental Investigation of Air Quality in Wet and Dry Turning, CIRP Ann. Manuf. Technol., 2000, 49, p 61-64

9. W.J. Deng, W. Xia, X.L. Zhao, and Y. Tang, Modelling of Temperature History During Machining of Cast Aluminium Alloy, Advanced Design and Manufacture to Gain a Competitive Edge, X.T. Yan, C. Jiang, and B. Eynard, Ed., Springer, New York, 2008, p 231-240

10. F. Ren and F. Liu, Estimation of Fine Dust Particles Distribution in Machining Workshop Based on COwZ Model, Chin. J. Mech. Eng., 2011, 24, p 1
11. M. Gliński, Dust Emission and Efficiency of Local Exhaust Ventilation During Cast Iron Grinding, Int. J. Occup. Saf. Ergon., 2002, 8, p 95

12. A. Djebara, V. Songmene, J. Kouam, and R. Khettabi, An Experimental Investigation on Dust Emission During Milling Process Using Statistical Analysis, Int. J. Adv. Mach. Forming Oper., 2012, 48, p 1537

13. L.Y. Gradus and Y.A. Popov, Methods of Decontaminating Emissions During Machining of Materials, Chem. Petroleum Eng., 1984, 20, p $57-59$

14. R. Khettabi, V. Songmene, and J. Masounave, Effects of Speeds, Materials, and Tool Rake Angles on Metallic Particle Emission During Orthogonal Cutting, J. Mater. Eng. Perform., 2010, 19, p 767-775

15. J. Kouam, V. Songmene, A. Djebara, and R. Khettabi, Effect of Friction Testing of Metals on Particle Emission, J. Mater. Eng. Perform., 2012, 21, p 965-972

16. B. Balout, V. Songmene, and J. Masounave, An Experimental Study of Dust Generation During Dry Drilling of Pre-cooled and Pre-heated Workpiece Materials, J. Manuf. Process., 2007, 9, p 23-34

17. V. Songmene, B. Balout, and J. Masounave, Clean Machining: Experimental Investigation on Dust Formation-Part I: Influence of Machining Parameters and Chip Formation, Int. J. Environ. Conscious Des. Manuf., 2008, 14, p 1-16

18. R. Khettabi, V. Songmene, and J. Masounave, Effect of Tool Lead Angle and Chip Formation Mode on Dust Emission in Dry Cutting, $J$. Mater. Process. Technol., 2007, 194, p 100-109

19. V. Songmene, B. Balout, and J. Masounave, Clean Machining: Experimental Investigation on Dust Formation. Part II: Influence of Machining Strategies and Drill Condition, Int. J. Environ. Conscious Des. Manuf., 2008, 14, p 17-33

20. A. Kremer and M. El Mansori, Influence of Nanostructured CVD Diamond Coatings on Dust Emission and Machinability of $\mathrm{SiC}$ Particle-Reinforced Metal Matrix Composite, Surf. Coat. Technol., 2009, 204, p 1051-1055

21. A. Djebara, "Métrologie des particules ultrafines d'usinage : optimisation de la caractérisation et de la mesure," École deTechnologie Supérieure (ÉTS), Montréal, p 150, 2012

22. C. Caceres and Q. Wang, Solidification Conditions, Heat Treatment and Tensile Ductility of Al-7Si-0.4 Mg Casting Alloys, AFS Trans., 1996, 104, p 1039-1044

23. F. Samuel, A. Samuel, and H. Liu, Effect of Magnesium Content on the Ageing Behaviour of Water-Chilled Al-Si-Cu-Mg-Fe-Mn (380) Alloy Castings, J. Mater. Sci., 1995, 30, p 2531-2540

24. M.C. Flemings, Solidification Processing, Metall. Mater. Trans. B, 1974, 5, p 2121-2134

25. Q. Wang, Microstructural Effects on the Tensile and Fracture Behavior of Aluminum Casting Alloys A356/357, Metall. Mater. Trans. A, 2003, 34, p 2887-2899

26. L. Zhang, Y. Jiang, Z. Ma, S. Shan, Y. Jia, C. Fan, and W. Wang, Effect of Cooling Rate on Solidified Microstructure and Mechanical Properties of Aluminium-A356 Alloy, J. Mater. Process. Technol., 2008, 207, p $107-111$

27. O.E. Sebaie, A. Samuel, F. Samuel, and H. Doty, The Effects of Mischmetal, Cooling Rate and Heat Treatment on the Eutectic Si Particle Characteristics of A319.1, A356.2 and A413.1 Al-Si Casting Alloys, Mater. Sci. Eng., A, 2008, 480, p 342-355

28. Y. Zedan, F. Samuel, A. Samuel, and H. Doty, Effects of Fe Intermetallics on the Machinability of Heat-Treated Al-(7-11)\% Si Alloys, J. Mater. Process. Technol., 2010, 210, p 245-257

29. R. Akhter, L. Ivanchev, and H. Burger, Effect of Pre/Post T6 Heat Treatment on the Mechanical Properties of Laser Welded SSM Cast A356 Aluminium Alloy, Mater. Sci. Eng., A, 2007, 447, p 192-196

30. S. Shivkumar, L. Wang, and C. Keller, Impact Properties of A356-T6 Alloys, J. Mater. Eng. Perform., 1994, 3, p 83-90 